Monique Machado

Rodrigues-Sobral'

Ohttps://orcid.org/0000-0001-5415-1240

Lara S. F. (arneiro ${ }^{2}$

(- https://orcid.org/0000-0002-4385-5290

Camila Castelo Branco Pupe'

Ohttps://orid. org/0000-0001-5590-435X

Osvaldo José Moreira do

Nascimento ${ }^{1}$

Ohttps://orcid.org/0000-0003-3516-485X

Cristina Andrade Sampaio 3

Ohttps://oridi.org/0000-0002-906-4425

Renato Sobral Monteiro-Junior $r^{1,4}$ (- https://orcid.org/0000-0002-8472-262X

\section{Influence of Islamic religion and spirituality on the well-being and quality of life of cancer patients: a meta-analysis and a hypothetical model of cerebral mechanisms}

\author{
Influência da religião e da espiritualidade islâmica no bem-estar \\ e na qualidade de vida de pacientes com câncer: uma metanálise \\ e um modelo hipotético de mecanismos cerebrais
}

DOI: $10.1590 / 0047-2085000000369$

\section{ABSTRACT}

Objective: To systematically analyze quantitative data about the effects of religion/spirituality and the well-being/quality of life of cancer patients. The second aim was to hypothesize a neurophysiological model of the association between religion/spirituality and the brain. Methods: This study met the PRISMA Statement and was registered at PROSPERO database. Randomized and Controlled trials investigating religion/spirituality and well-being/quality of life of cancer patients were included. Based on neuroimaging and neurophysiology studies, a neuroanatomical model was developed to hypothesize the relationship between neuroscience and religion/spirituality. Results: A large effect size was found on the improvement of well-being/quality of life (SMD = 3.90 [2.43-5.38], $p<0.01$ ). Heterogeneity was high among studies $\left(I^{2}=98 \%, p<0.01\right)$. Specific regions of the brain, such as the temporal lobes, amygdalae and hippocampus, regions from the limbic system, were hypothesized to take part in the religion/spirituality phenomena and the well-being/quality of life improvement. Conclusion: Religion/spirituality intervention, mainly the Islamic, promotes an improvement on wellbeing/quality of life of cancer patients.

\section{KEYWORDS}

Religious beliefs, spiritual therapies, quality of life, neoplasms, cancer.

\section{RESUMO}

Objetivo: Analisar sistematicamente dados quantitativos sobre os efeitos da religião/espiritualidade e o bem-estar/qualidade de vida de pacientes com câncer. O segundo objetivo foi levantar a hipótese de um modelo neurofisiológico da associação entre religião/espiritualidade e o cérebro. Métodos: Este estudo seguiu as recomendações do PRISMA e foi registrado no PROSPERO. Estudos randomizados e controlados investigando religião/espiritualidade e o bem-estar/qualidade de vida de pacientes com câncer foram incluídos. Com base em estudos de neuroimagem e neurofisiologia, um modelo neuroanatômico foi desenvolvido para hipotetizar relações entre neurociência e religião/espiritualidade. Resultados: Um tamanho de efeito grande foi encontrado na melhoria do bem-estar/qualidade de vida (SMD = 3,90 [2,43-5,38], $\mathrm{p}<0,01)$. A heterogeneidade foi alta entre os estudos $\left(I^{2}=98 \%, p<0,01\right)$. Regiões específicas do cérebro, como lobos temporais, amídalas e hipocampo, regiões do sistema límbico, foram hipotetizadas como participantes dos fenômenos religião/espiritualidade e melhoria do bem-estar/qualidade de vida. Conclusão: A intervenção religiosa/espiritual, principalmente islâmica, promove melhora no bem-estar/qualidade de vida em pacientes com câncer.

\section{PALAVRAS-CHAVE}

Crenças religiosas, terapias espirituais, qualidade de vida, neoplasmas, câncer.
1 Federal Fluminense University, Neurology Department, Niterói, RJ, Brazil.

2 University Institute of Maia (ISMAI), Physical Education Department, Maia, Portugal.

3 Montes Claros State University, Mental Health Department, Montes Claros, MG, Brazil.

4 Montes Claros State University, Physical Education Department, Montes Claros, MG, Brazil.

Address for correspondence: Renato Sobral Monteiro-Junior. Universidade Estadual de Montes Claros, Campus Universitário Prof. Darcy Ribeiro. Av. Prof. Rui Braga, s/n, Vila Mauriceia - 39401-089 - Montes Claros, MG, Brasil. renato.monteiro@unimontes.br 


\section{INTRODUCTION}

Religion is a universal aspect of the culture and may be understood as a search for something sacred, involving beliefs in supernatural phenomena and rituals. Furthermore, religion is related to social factors, with the participation of groups of persons who share the same faith. Otherwise, spirituality is defined as an individual phenomenon with no established religious affiliation. Both religion and spirituality are associated to well-being, intrinsic peace, gratitude and moral principles of an individual. These phenomena are strongly associated to mental and physical health, and social relationships ${ }^{1}$.

As an individual and/or social phenomenon religion and spirituality arises as a way to face severe health and social problems. Studies have shown that religion and spirituality can be applied as complementary therapy for cancer patients, ameliorating pain perception, distress and anxiety ${ }^{2,3}$.

Cancer diagnosis may be devastating and usually triggers emotional and psychological disturbances, affecting patient's mental health. Fear and anguish may arise due to the uncertainties related to treatment, prognosis, physical appearance and stigma, and are associated factors to patients' anxiety, depression, poor quality of life and low well-being ${ }^{2,4-7}$.

Studies have shown that well-being and quality of life are unlike in different patients who experienced the spirituality as a part of the treatment ${ }^{8}$. However, although many studies report religion and spirituality as a complementary therapy for patients with many diseases ${ }^{9-12}$, to our knowledge there is no available meta-analysis investigating the application of such practice as an intervention to improve well-being and quality of life of cancer patients, especially including western and eastern studies with no religion and spiritual distinction. Therefore, the aim of this study was to systematically review and analyze the literature about the effects of religion and spirituality on the well-being and quality of life of cancer patients.

Secondarily, a hypothetical association model between religion and spirituality and the brain was elaborated to elucidate the relationship between neuroscience and faith. Studies investigating the relationship between religion/ spirituality and brain mechanisms involved in the sensation, faith and belief process were approached ${ }^{11,12}$. Religious and spiritual practices may involve prayers, mediation, standing, bending, sitting, and at the same time giving grace to the spirit of God. A study using positron emission tomography (PET) found some participants decreased cortical activity in the frontal lobe, while in the anterior cingulate gyrus there was an increase in activity ${ }^{13}$. These areas have a strong connection with the amygdala, responsible for emotional responses, periaqueductal gray matter, primary site for modulation of certain circuits related to pain and emotions, and to the mid-dorsal and anterior thalamic nuclei, involved in some functions, such as learning, memory and attention ${ }^{13}$.

\section{METHODS}

\section{Register}

This systematic review followed the Referred Reporting Items for Systematic Reviews and Meta-Analyses (PRISMA)14 and was registered in the International Prospective Register of Systematic Review (PROSPERO) under the protocol CRD42020154006.

\section{Eligibility and exclusion criteria}

PICOS strategy was applied to establish specific parameters that studies should present: P - cancer patients; I - religion/ spirituality/faith; $\mathrm{C}$ - any comparator; $\mathrm{O}$ - well-being and/ or quality of life; and $\mathrm{S}$ - randomized and controlled trial. Therefore, only experimental studies investigating the effects of religion/spirituality/faith on the well-being and/or quality of life of cancer patients were included in this review.

No restriction was applied to language of studies, type of religion and publication period. The following exclusion criteria were applied: 1) studies aiming the opposite to this meta-analysis, 2) unclear mean and standard deviation measures, 3) qualitative approaches, 4) studies with cured cancer patients, 5) studies that assessed patients' family members or their caregivers.

\section{Search strategy}

PubMed/MEDLINE, Scopus and Web of Science were used to retrieve studies. The search started October 2019 and finished in December 2020. The following search-terms were browsed in the databases: religion, spirituality, cancer, well-being and quality of life. Similar words were searched on the Health Sciences Descriptors (https://decs.bvsalud.org) and Medical Subject Headings (https://www.ncbi.n/m.nih.gov/mesh/). The full search strategy handled in the PubMed/MEDLINE can be seen : ((((quality of life[Title/Abstract] OR well-being[Title/ Abstract]) OR health-related quality of life[Title/Abstract]) $O R$ life quality[Title/Abstract]) OR mental health[Title/Abstract]) AND (((cancer[Title/Abstract] OR tumor[Title/Abstract]) OR neoplasm[Title/Abstract]) OR malignancy[Title/Abstract])) AND (()((religion[Title/Abstract] OR religious beliefs[Title/ Abstract]) OR religious[Title/Abstract]) OR spirituality[Title/ Abstract]) OR spiritualities[Title/Abstract]) OR faith[Title/ Abstract]) AND Clinical Trial[ptyp].

\section{Data collection and study selection}

Data collection followed a standardized procedure that was performed by one research (MMRS): 1) reading study titles, 2) reading study abstracts, and 3) reading full articles. 
A Microsoft Excel spreadsheet was created to record the extracted data from the included studies: first author, year of publication, country in which the study was conducted, sample size in each group, mean and standard deviation preand post-intervention in each group, and the type of cancer.

\section{Data synthesis}

According to the variety of instruments used to assess the outcomes herein investigated, we decided to analyze the well-being and quality of life as a single variable, providing a possibility to summarize data in a grouped effect analysis with an enough number of studies $(n=5)$. Studies that evaluated well-being and quality of life with more than one scale were analyzed according to the number of instruments. For example, if a study assessed well-being using two different scales, these data were displayed as two results. The Standardized Mean Difference (SMD) was calculated and a random effect adjustment applied. The heterogeneity index $\left(I^{2}\right)$ was verified to estimate potential discrepancies within studies. Analyses were conducted in the Review Manager 5.3.

\section{Risk of individual bias}

The Jadad Scale ${ }^{15}$ was used to classify studies methodologically, exposing any weakness. The level of evidence was standardized according a cut-off point previously established $^{16}$ : Level $A=05$ points; Level $B=03-04$ points; Level $\mathrm{C}=<03$ points; where $\mathrm{A}$ and $\mathrm{C}$ mean the best and the worst evidence, respectively.

\section{Publication bias}

A visual inspection of the Funnel Plot was applied to identify data dispersion (Y-axis) and effect size (X-axis) of each study. An imbalance in the position of studies inside the Funnel Plot indicates publication bias ${ }^{16}$.

\section{Hypothetical model of the religion/spirituality/ faith and the relationship with the brain}

Based on neurophysiology and neuroimage studies $^{17}$, a neuroanatomical model was created to hypothesize the relationship between neuroscience and religion/spirituality/ faith. 3D Brain (https://www.brainfacts.org) app was used to elaborate the model.

\section{RESULTS}

From all eligible studies $(n=884)$, five articles were selected and analyzed (Figure 1). According our PICOS strategy only randomized controlled trials from Iran were included and analyzed in the present study. Different scales were identified evaluating well-being 2,3,18: 1) Palutzian and Ellison Spiritual Well-being Questionnaire (SWB Questionnaire); 2) Spiritual well-being scale; 3) Persian version of 12-item Functional
Assessment of Chronic IIIness Therapy-Spiritual Well-Being (FACIT-Sp12) questionnaire. Quality of life in three studies $5^{5,7,18}$ was also evaluated with different instruments: 1) European Organization for Research and Treatment of Cancer Quality of Life (EORTC QLQ-C30) and 2) The Cancer quality-of-life questionnaire (QLQ)-C30 core questionnaire.

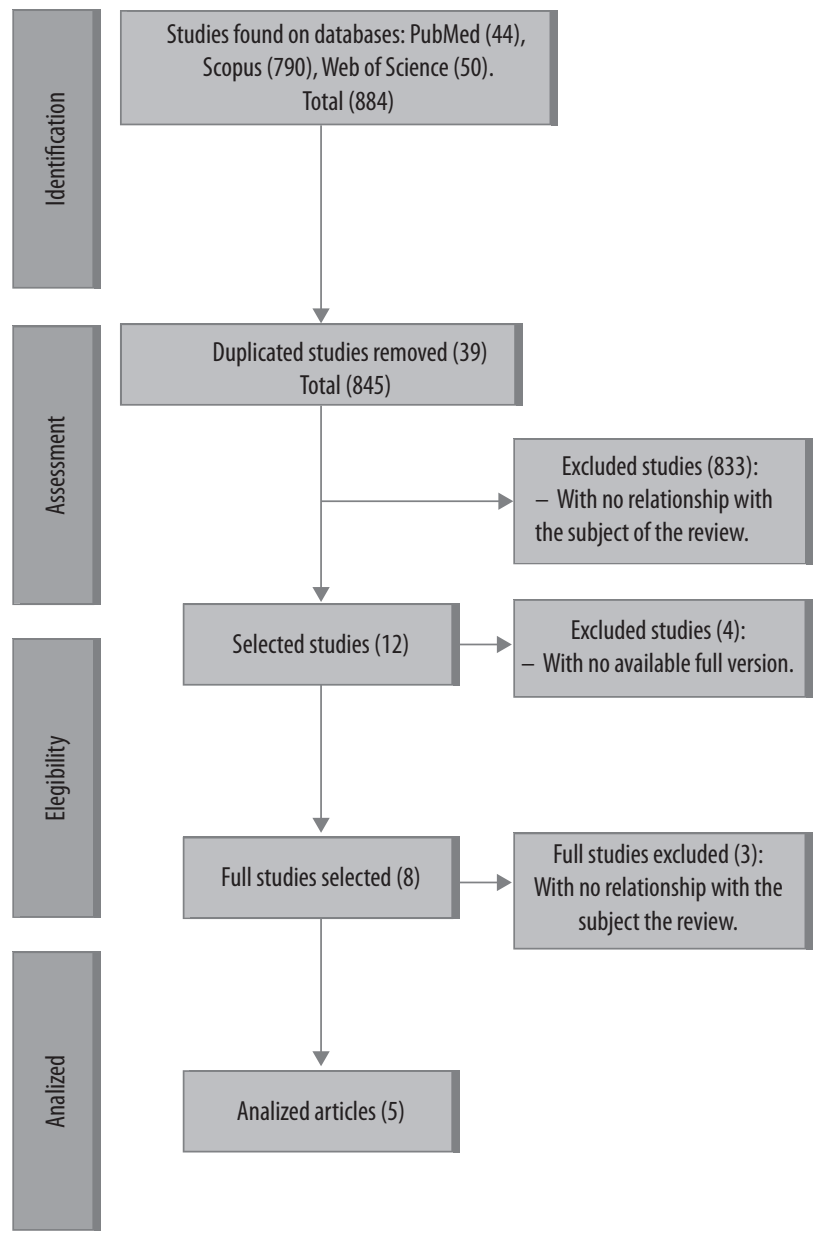

Figure 1. Articles screening and inclusion flowchart.

Although our purpose was to investigate different religions, all included studies were conducted in Iran, a Muslim republic. Two studies ${ }^{2,3}$ included participants if they were from Shiite regimen, while the others ${ }^{5,18,19}$ did not specify the regimen as exclusion criterion. Table 1 shows detailed data from each analyzed study.

\section{Data synthesis}

A large effect size was found in well-being/quality of life after cancer patients have undergone religious and spirituality intervention ( $S M D=3.90$ [2.43-5.38], $p<0.01$ ) (Figure 2). Heterogeneity was high within studies $\left(1^{2}=98 \%, p<0.01\right)$. 
Table 1. Details of the studies selected for the meta-analysis, by author/year; religion; $\mathrm{N}$ in the control group and $\mathrm{N}$ in the experimental group; instrument used and type of cancer prevalent in each study

\begin{tabular}{|c|c|c|c|c|c|c|}
\hline Author/Year & Country & Religion & N control & $\begin{array}{c}\mathbf{N} \\
\text { experimental }\end{array}$ & Instrument Used & Type of cancer \\
\hline $\begin{array}{l}\text { Amir Musarezaie, } \\
2015\end{array}$ & Iran & Shiite & 32 & 32 & $\begin{array}{l}\text { - Socio-demographic questionnaire; } \\
\text { - Palutzian and Ellison Spiritual Well-being Questionnaire } \\
\text { (SWB Questionnaire). }\end{array}$ & - Leukemia \\
\hline $\begin{array}{l}\text { Mahbobeh } \\
\text { Sajadi, } 2018\end{array}$ & Iran & Shiite & 21 & 21 & $\begin{array}{l}\text { - Socio-demographic questionnaire; } \\
\text { - Spiritual well-being scale (SWBS). }\end{array}$ & $\begin{array}{l}\text { - Breast cancer } \\
\text { - Gastrointestinal } \\
\text { - Others }\end{array}$ \\
\hline $\begin{array}{l}\text { Camelia Rohani, } \\
2015\end{array}$ & Iran & Not specified. & 162 & 210 & $\begin{array}{l}\text { - Socio-demographic questionnaire; } \\
\text { - European Organization for Research and Treatment of } \\
\text { Cancer Quality of Life (EORTC QLQ-C30); } \\
\text { - The sense of Coherence (SOC) scale; } \\
\text { - The Spiritual Perspective Scale (SPS); } \\
\text { - The Brief Religious Coping (Brief RCOPE). }\end{array}$ & - Breast cancer \\
\hline $\begin{array}{l}\text { Najmeh Jafari, } \\
2013^{*}\end{array}$ & Iran & Not specified. & 34 & 31 & $\begin{array}{l}\text { - Socio-demographic questionnaire; } \\
\text { - Persian version of } 12 \text {-item Functional Assessment of } \\
\text { Chronic Illness Therapy-Spiritual Well-Being (FACIT-Sp12) } \\
\text { questionnaire; } \\
\text { - European Organization for Research and Treatment of } \\
\text { Cancer Quality of Life (EORTC QLQ-C30); }\end{array}$ & - Breast cancer \\
\hline $\begin{array}{l}\text { Najmeh Jafari, } \\
2013^{\star \star}\end{array}$ & Iran & Not specified. & 34 & 31 & $\begin{array}{l}\text { - Socio-demographic questionnaire. } \\
\text { - The European Organization for Research and Treatment } \\
\text { of Cancer Quality of Life Group (EORTC QLG); } \\
\text { - The Cancer quality-of-life questionnaire (QLQ)-C30 core } \\
\text { questionnaire. }\end{array}$ & - Breast cancer \\
\hline
\end{tabular}

* Reference 18.

${ }^{\star \star}$ Reference 5 .

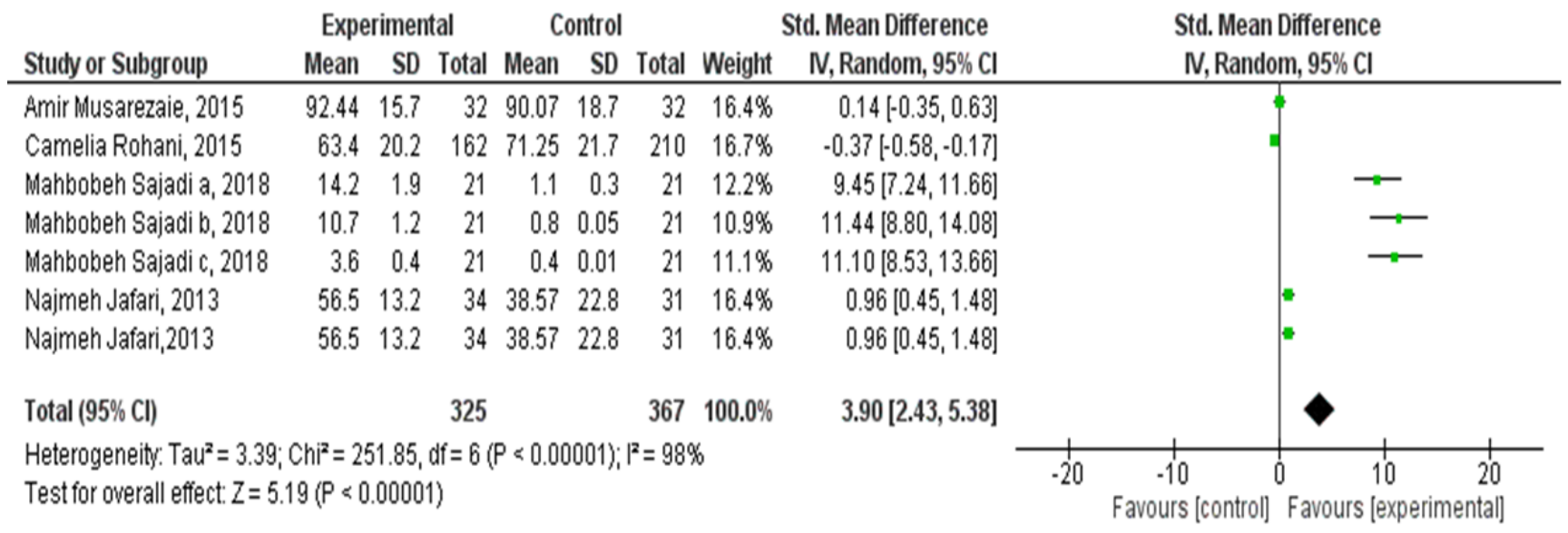

Figure 2. Forest Plot showing the effect of religion/spirituality on well-being/quality of life.

* Reference 18.

${ }^{\star \star}$ Reference 5. 


\section{Risk of individual bias}

According to the Jadad Scale four studies had low risk of bias (score $\geq 3$ ) 2,3,5,18 and one ${ }^{19}$ presented a high risk (score <3) (Table 2).

\section{Publication bias}

Data asymmetry, that presented a meaningful publication bias, was observed in the Funnel Plot visual inspection (Figure 3).

\section{Hypothetical model of the religion and spirituality and faith and the relationship with the brain}

Many brain mechanisms are associated to religious belief. Brain regions such as temporal lobes, amygdalae, hippocampus and other limbic regions ${ }^{17}$ are related to these neurobiological mechanisms. The activation pattern of these structures may be related to mystical and supernatural beliefs, hallucination and spiritual possession, among others ${ }^{20}$.
This hypothetical model supposes that the aforementioned activation during a religious and spiritual intervention may occur. Short- and long-term neurophysiological alterations could appear in patients' brain according to the activation pattern, leading them to experience well-being/quality of life (Figure 4), and therefore explaining the results of this meta-analysis.

\section{DISCUSSION}

This meta-analysis showed a large improvement of wellbeing/quality of life of cancer patients who experienced a religious and spiritual intervention. Such findings can be explained according to the predictive processing model of the beliefs in the brain, as shown in our hypothetical model. This model explains how religion and spirituality affects behavior through the activation of brain regions associated to the limbic system. For instance, the amygdalae is involved

Table 2. Individual bias analysis

\begin{tabular}{|c|c|c|c|c|c|c|}
\hline Study & $\begin{array}{l}\text { Study described } \\
\text { as randomized? }\end{array}$ & $\begin{array}{l}\text { Study described } \\
\text { as double blind? }\end{array}$ & $\begin{array}{l}\text { Was there a } \\
\text { description of } \\
\text { losses? }\end{array}$ & $\begin{array}{c}\text { Appropriate } \\
\text { Randomization? }\end{array}$ & $\begin{array}{c}\text { Blindly } \\
\text { Appropriate? }\end{array}$ & Total \\
\hline Amir Musarezaie, 2015 & $x$ & $x$ & NA & $x$ & $x$ & 4 \\
\hline Camelia Rohani, 2015 & NA & NA & $x$ & NA & NA & 1 \\
\hline Mahibibeh Sajadi a b c, 2018 & $x$ & NA & $x$ & $x$ & $x$ & 4 \\
\hline Najameh Jafari, 2013* & $x$ & NA & $x$ & $x$ & $x$ & 4 \\
\hline Najameh Jafari**, 2013 & $x$ & NA & $\mathrm{x}$ & $x$ & $x$ & 4 \\
\hline
\end{tabular}

NA: Not Applicable.

* Reference 18

${ }^{\star *}$ Reference 5.

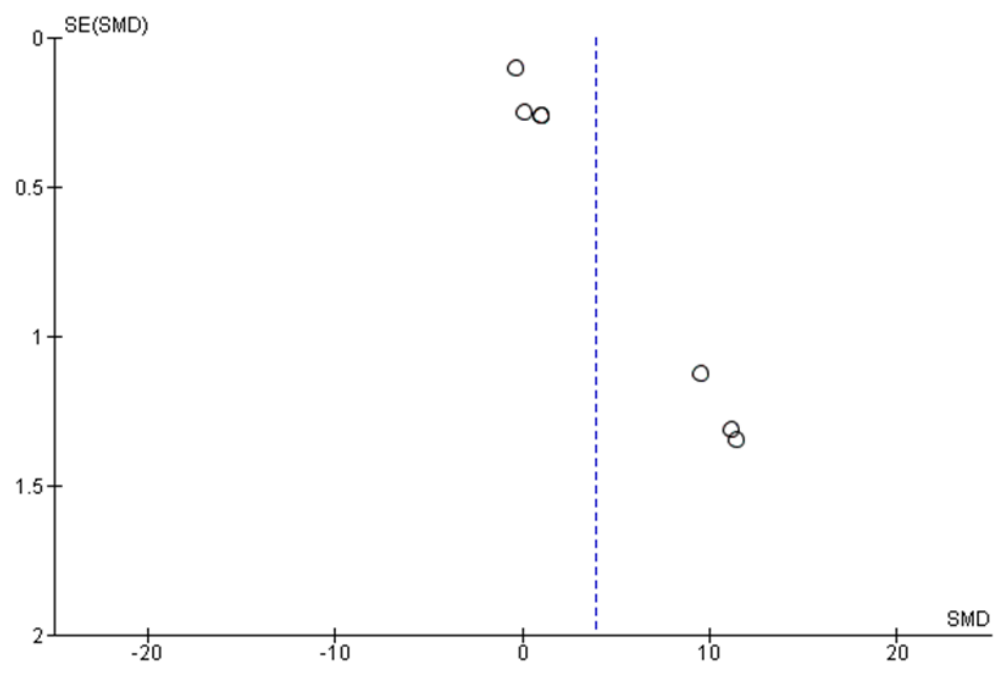

Figure 3. Funnel Plot showing the publication bias, due to study asymmetry. 
A

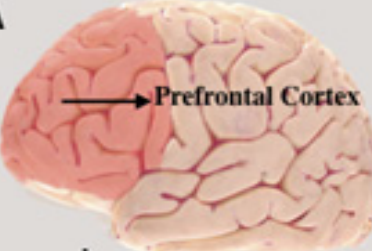

I

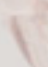

B

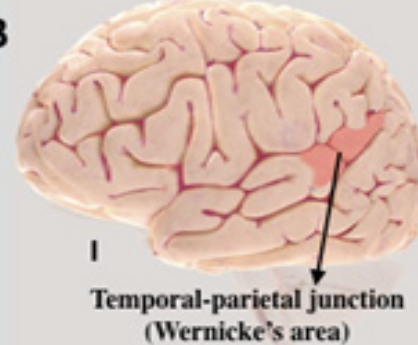

C

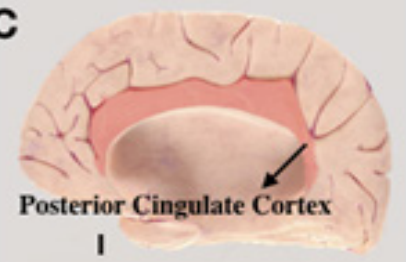

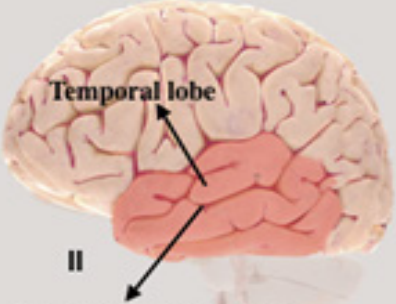

Superior Temporal Sulcus
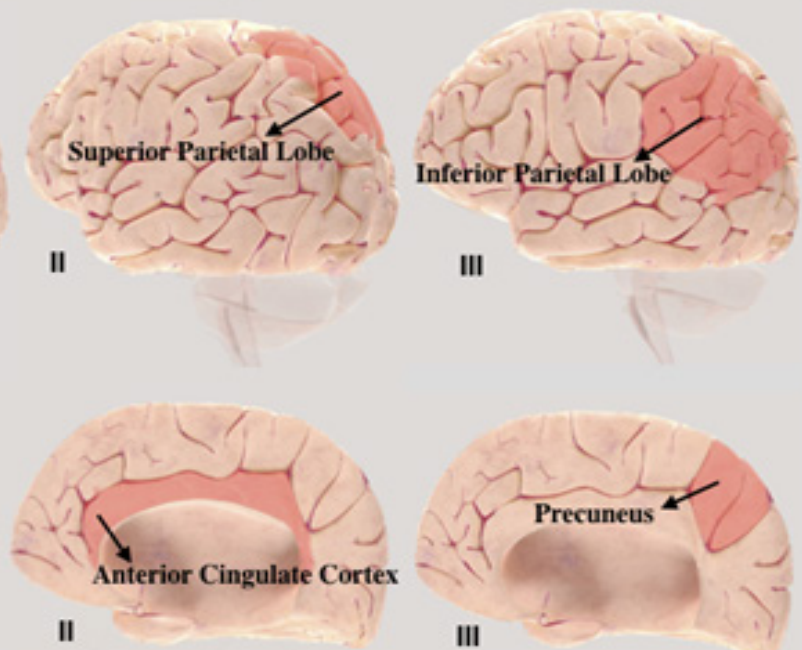

Right and left Hippocampus

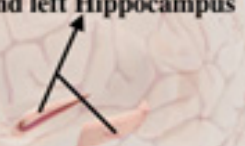

III

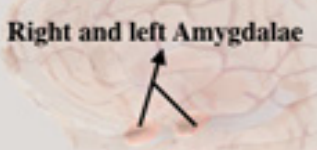

IV
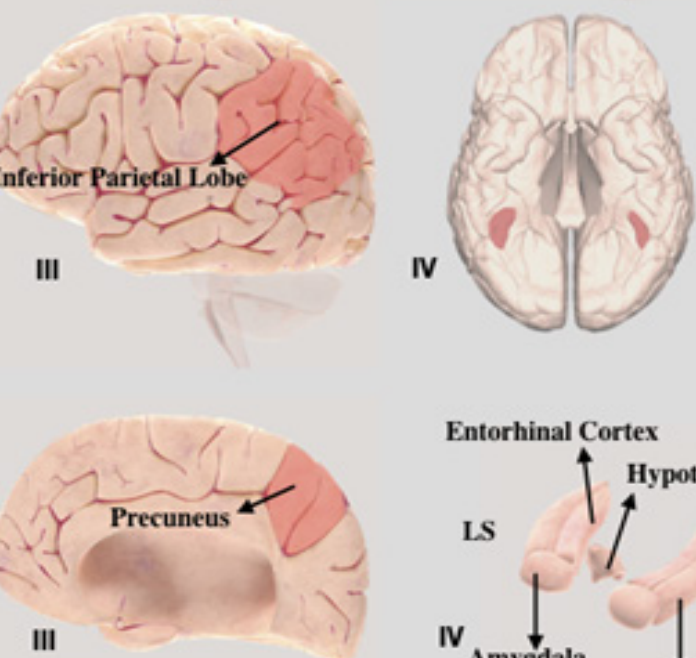

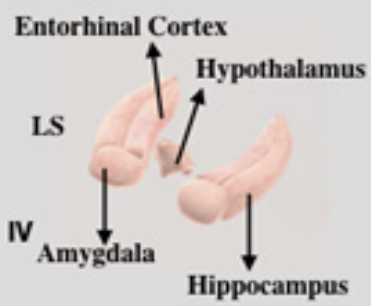

Figure 4. Hypothetical model displaying the association among brain regions, faith/religion/spirituality and well-being/quality of life. Brain regions: Prefrontal Cortex (A-I), Temporal Lobe and Superior Temporal Sulcus (A-II), Hippocampus (A-III), Amygdalae (A-IV), Temporal-parietal Junction (B-I), Superior Parietal Lobe (B-II), Inferior Parietal Lobe (B-III), Fusiform Face Area (B-IV), Anterior Cingulate Cortex (C-I), Posterior Cingulate Cortex (C-II), Precuneus (C-III), LS - Limbic System (C-IV). A-I function: Planning, decision-making, working memory, social recognition, reasoning, intentionality, judgement. A-II function: Auditive perception, emotion, memory. A-III function: Short- and long-term memories, navigational skills, emotional processing. A-IV function: Emotional perception, fear, fight and flight action. B-I function: Face recognition, visuospatial perception, auditive-visual-somesthetic integration. B-Il: Mental imagery, attention, visuospatial perception, spatial orientation, somatosensory integration. B-III: Self-referential processing, language, sensory information, body image, calculation. B-IV: Facial and objects recognition. C-I: memory retrieval, emotional regulation, self-thinking. C-II: error detection, social processing, attention, motivation, emotional regulation. C-III: navigational skills, episodic memory, mental imagery, self-consciousness. C-IV: emotional processing, pleasure sense, alertness, memory, surveillance behavior, thirst, hunger, thermoregulation. Based on van Elk, M. \& Aleman, A study ${ }^{19}$ religious and spirituality experiences are processed by specific brain circuitry, such as: A-III $\rightarrow$ A-IV $\rightarrow A-\| \rightarrow B$-IV (visions, hallucinations, Déjà-vu experiences); B-I $\rightarrow B-\| \rightarrow B$-III (mystical experiences, self-transcendence, outof-body experiences, feeling of a presence); C-I $\rightarrow C-\|I \rightarrow B-\| I I \rightarrow A-\|$ (mystical experiences, Ego-dissolution, reflective religious beliefs); $A-I \rightarrow A-\| \rightarrow B-I$ (prayer, belief in personal God, over-attribution of agency). C-I $\rightarrow$ A-I $\rightarrow C-I V$ (openness to religious authority and rituals).

in emotions, feelings, hallucination and fear, which are common in several religions ${ }^{20}$. However, other factors such as social and cultural aspects should be considered in the beliefs modeling ${ }^{17}$. It means that the brain modulates religious and spiritual experiences in line with the environment where a person lives, shaping neurophysiological mechanisms ${ }^{17}$. The interaction between brain and environmental experiences reinforces feedback as a loop, that could be related to the clinical improvements in the well-being and quality of life.

Studying religion and spirituality requires knowledge about the culture in which the context is embedded, as beliefs affect neurocognitive mechanisms ${ }^{17,21}$. In this study all analyzed articles were from Iran, a country with Shiite regimen, which represents $15 \%$ of the Muslim population. This religious doctrine is influenced by an idealism, similar to Catholicism, because persons try to justify the suffering and bad things in the world. They believe that the suffering is needed to forgiveness of sins. In this context, death, pain and sacrifice play a transcendent role: find Allah, the Muslim God. Muslims also believe that Allah created the diseases and their related suffering brings people and Allah together through prayere22,23. In a neuroscientific analysis we could infer that the aforementioned culture would influence, even partially, the limbic system activation to generate responses such as fear and remorse (processed in the 
amygdalae), pleasure and satisfaction, these both related to the role of dopaminergic circuitry between nucleus accumbens and tegmental ventral area 17,20,21.

Findings herein shown provide reasonable elements to understand religion and spirituality as a biological, neurocognitive, environmental and social product. Notwithstanding, religious and spiritual therapy could improve subjective perceptions of well-being and quality of life according to emotions, feelings, memory, pleasure and fear associated to a positive belief (Figure 3$)^{20}$. We highlight the activation of other brain regions associated to prayer similar to meditation, such as dorsolateral prefrontal cortex, temporoparietal and subcortical regions ${ }^{21}$. These several brain structures and their functional circuitry should be studied to optimize our comprehension of the complexity of the religion and spirituality processing in the brain.

It is important to highlight the predictive processing model in which exteroceptive and interoceptive domains related to the environmental experiences and neurophysiological phenomena interact, hence influencing the individual behavior. In summary, interoceptive domain is related to an improved autonomic control due to the religious and spiritual and cultural experiences (exteroceptive domain), ameliorating cancer patients perception of well-being and quality of life ${ }^{17}$.

Religious beliefs may affect somatic responses such as the sensitivity to pain. Moreover, prayer may trigger a mechanism known as response-relaxing, in which physiological phenomena occur when a person reaches a relaxed state $^{21}$. Prayer and other rituals are performed many times as a repetitive practice. The repetition of this practice could cause physiological responses, for instance, metabolism and heart rate reduction ${ }^{21}$, promoting calm and relaxation, improving well-being and quality of life.

Although studies herein analyzed show an improvement on well-being ${ }^{2,3,18}$ and quality of life ${ }^{5,18,19}$ of cancer patients after religious/spiritual intervention, some limitations are shown: 1) the small number of studies, 2) different scales to measure outcomes, and 3) Islamic religion predominance. According our results it is not possible generalize these results to the other religions. Furthermore, well-being and quality of life as a single outcome should be interpreted with caution, as these variables may have different meanings. New studies in this field will allow us a comprehensive isolated analysis of each outcome.

In conclusion, therapies addressing Islamic religion and spirituality likely promote an improvement on wellbeing/quality of life in cancer patients. This finding may be associated to different brain mechanisms involved in beliefs, emotion, feelings, pleasure and their association with environmental and social experiences. Further studies should investigate different religions or spirituality manifestations to amplify the understanding of this matter.

\section{ACKNOWLEDGEMENT}

The authors are grateful for the academic training grant from Capes - Coordenação de Aperfeiçoamento de Pessoal de Nível Superior. Process number: 88882.456142/2019-01

\section{CONFLICT OF INTERESTS}

The authors declare no conflict of interest.

\section{INDIVIDUAL CONTRIBUTIONS}

\begin{abstract}
Monique Machado Rodrigues-Sobral, Lara S. F. Carneiro, Camila Castelo Branco Pupe, Osvaldo José Moreira do Nascimento, Cristina Andrade Sampaio, Renato Sobral Monteiro-Junior - Conception and design of studies, or to the analysis and interpretation of data; contributed to the writing of the article, or critically reviewed its intellectual content; approved its final version for publication.
\end{abstract}

\section{REFERENCES}

1. Koenig HG. Religion, Spirituality, and Health: The Research and Clinical Implications. ISRN Psychiatry. 2012;2012:1-33.

2. Musarezaie A, Ghasemipoor M, Momeni-Ghaleghasemi T, Khodaee M, Taleghani F. A Study on the Efficacy of Spirituality-Based Intervention on Spiritual Well Being of Patients with Leukemia: A Randomized Clinical Trial. Middle East J Cancer. 2015;6(2):97-105.

3. Sajadi M, Niazi N, Khosravi S, Yaghobi A, Rezaei M, Koenig HG. Effect of spiritual counseling on spiritual well-being in Iranian women with cancer: A randomized clinical trial. Complement Ther Clin Pract. 2018;30:79-84.

4. Schreiber JA, Brockopp DY. Twenty-five years later - What do we know about religion/ spirituality and psychological well-being among breast cancer survivors? A systematic review. J Cancer Surviv. 2012;6(1):82-94.

5. Jafari N, Zamani A, Farajzadegan Z, Bahrami F, Emami H, Loghmani A. The effect of spiritual therapy for improving the quality of life of women with breast cancer: A randomized controlled trial. Psychol Health Med. 2013;18(1):56-69.

6. Zamaniyan S, Bolhari J, Naziri G, Akrami M, Hosseini S. Effectiveness of Spiritual Group Therapy on Quality of Life and Spiritual Well-Being among Patients with Breast Cancer. Iran J Med Sci. 2016;41(2):140-4.

7. Bai M, Lazenby M, Jeon S, Dixon J, McCorkle R. Exploring the relationship between spiritual well-being and quality of life among patients newly diagnosed with advanced cancer. Palliat Support Care. 2015;13(4):927-35.

8. Counted V, Possamai A, Meade T. Relational spirituality and quality of life 2007 to 2017: An integrative research review. Health Qual Life Outcomes. 2018;16(1):75.

9. Salsman JM, Pustejovsky JE, Jim HSL, Munoz AR, Merluzzi TV, George L, et al. A metaanalytic approach to examining the correlation between religion/spirituality and mental health in cancer. Cancer. 2015;121(21):3769-78.

10. Abu HO, Ulbricht C, Ding E, Allison JJ, Salmoirago-Blotcher E, Goldberg RJ, et al. Association of religiosity and spirituality with quality of life in patients with cardiovascular disease: a systematic review. Qual Life Res. 2018;27(11):2777-97.

11. Jim HS, Pustejovsky JE, Park CL, Danhauer SC, Sherman AC, Fitchett G, et al. Religion, spirituality, and physical health in cancer patients: A meta-analysis. Cancer. 2015;121(21):3760-8. 
12. Ross L. The spiritual dimension: its importance to patients' health, well-being and quality of life and its implications for nursing practice. Int J Nurs Stud. 1995;32(5):457-68.

13. Griffioen G, Matheson GJ, Cervenka S, Farde L, Borg J. Serotonin 5-HT1A receptor binding and self-transcendence in healthy control subjects - A replication study using Bayesian hypothesis testing. PeerJ. 2018; 6:e5790.

14. Moher D, Liberati A, Tetzlaff J, Altman DG. PRISMA 2009 Checklist. Ann Intern Med. 2014:151:264-9.

15. Jadad AR, Moore Ra, Carroll D, Jenkinson C, Reynolds DJ, Gavaghan DJ, et al. Assessing the Quality of Reports of Randomized Clinical Trials: Is Blinding Necessary? Control Clin Trials. 1996;17(1):1-12.

16. Monteiro-Junior RS, De Tarso Maciel-Pinheiro P, Da Matta Mello Portugal E, Da Silva Figueiredo LF, Terra R, Carneiro LSF, et al. Effect of exercise on inflammatory profile of older persons: Systematic review and meta-analyses. J Phys Act Health. 2018;15(1):64-71.

17. van Elk M, Aleman A. Brain mechanisms in religion and spirituality: An integrative predictive processing framework. Neurosci Biobehav Rev. 2017;73:359-78.
18. Jafari N, Farajzadegan Z, Zamani A, Bahrami F, Emami H, Loghmani A, et al. Spiritual therapy to improve the spiritual well-being of Iranian women with breast cancer: A randomized controlled trial. Evid Based Complement Alternat Med. 2013;2013:353262.

19. Rohani C, Abedi HA, Omranipour R, Langius-Eklöf A. Health-related quality of life and the predictive role of sense of coherence, spirituality and religious coping in a sample of Iranian women with breast cancer: A prospective study with comparative design. Health Qual Life Outcomes. 2015;13(1).

20. Joseph R. The Limbic System and the Soul: Evolution and the neuroanatomy of religious experience. Zygon(r): 2003;36(1):105-36.

21. Schjoedt $U$. The religious brain: A general introduction to the experimental neuroscience of religion. Method Theory Study Relig. 2009;21(3):310-39.

22. Rezaei M, Adib-Hajbaghery M, Seyedfatemi N, Hoseini F. Prayer in Iranian cancer patients undergoing chemotherapy. Complement Ther Clin Pract. 2008;14(2):90-7.

23. Cheraghi MA, Payne S, Salsali M. Spiritual aspects of end-of-life care for Muslim patients: experiences from Iran. Int J Palliat Nurs. 2005;11(9):468-74. 